\title{
LA TOMOGRAFÍA COMPUTARIZADA DE HAZ CÓNICO
}

\author{
${ }^{1}$ Antonio F. Finlayson, ${ }^{2}$ Rodolfo Epifanio \\ ${ }^{1}$ Cirujano Dental U. de Panamá, Postgrado en Odontopediatría U. de Chile, \\ Postgrado en Ortodoncia U. de Chile, Maestría en Docencia Superior UNIEDPA. \\ ${ }^{2}$ Cirujano Dental U. de Panamá, Residencia en Odontología General y Hospitalaria U. de Puerto Rico, \\ Residencia en Medicina Oral Lousiana State U., Posgrado en Docencia Superior U. de Panamá.
}

Autor responsable de correspondencia: Antonio F. Finlayson

Correo electrónico: finlaysonantonio@hotmail.com

\begin{abstract}
RESUMEN:
La aplicación clínica de las imágenes craneofaciales tridimensionales es uno de los temas más interesantes y revolucionarios en la odontología. Los sistemas de tomografía computarizada de haz cónico (TCHC) han sido diseñados para obtener imágenes de tejidos duros de la región maxilofacial. La TCHC es capaz de proveer una resolución sub-milimétrica en imágenes de alta calidad diagnóstica, con tiempos de escaneo cortos (10-70 segundos) y dosis de radiación reportada 15 veces menos que aquellas necesarias para los escaneos de tomografía computarizada convencional. El aumento de la disponibilidad de esta tecnología provee al odontólogo clínico de una modalidad imagenológica capaz de lograr representaciones tridimensionales del esqueleto maxilofacial con un grado de distorsión mínimo. Este artículo es una revisión de las aplicaciones específicas de los diferentes modos de imágenes de la tomografía computarizada de haz cónico en la práctica clínica odontológica. [Finlayson AF, Epifanio R. La tomografia computarizada de haz cónico. Ustasalud 2008; 7: 125 - 131]
\end{abstract}

Palabras clave: Radiografía, Tomografia, Instrumentos Radiográficos, Diagnóstico

\section{CONE-BEAM COMPUTER TOMOGRAPHY SYSTEM}

\begin{abstract}
The clinical application of 3-dimensional craniofacial imaging is one of the most exciting and revolutionary topics in dentistry. Conebeam computed tomography ( $\mathrm{CBCT}$ ) systems have been designed for imaging hard tissues of the maxillofacial region. $\mathrm{CBCT}$ is capable of providing sub-millimeter resolution in images of high diagnostic quality, with short scanning times (10-70 seconds) and radiation dosages reportedly up to 15 times lower than those of conventional CT scans. Increasing availability of this technology provides the dental clinician with an imaging modality capable of providing a 3-dimensional representation of the maxillofacial skeleton with minimal distortion. This article provides an overview of he specific application of various CBCT display modes to clinical dental practice.
\end{abstract}

Key words: Radiography, Tomography, X-ray computed/instrumentation, Diagnose.

Recibido para publicación: 9 de julio de 2008. Aceptado para publicación: 13 de noviembre de 2008.

\section{INTRODUCCIÓN}

Las radiografias convencionales de uso en odontología permiten la obtención de imágenes en dos planos o dimensiones. Las radiografias han sido usadas en odontología en el diagnóstico clínico desde que la radiación X fue descubierta por Roentgen, sin embargo, una de las limitaciones más importantes es la imposibilidad de reproducir los tejidos estudiados en todas sus dimensiones además del riesgo de efectos acumulativos por radiación ionizante. ${ }^{1}$ En la actualidad se dispone de una técnica innovadora que permite la reproducción tridimensional de los tejidos a niveles de radiación extremadamente ba- jos. Esta tecnología es la tomografía computarizada de haz cónico.

El sistema de tomografía computarizada de haz cónico es una técnica de imagenología moderna que permite al clínico capturar y analizar la anatomía ósea o patologías en tres dimensiones. La aplicación de esta tecnología es posible debido a los avances logrados en la tecnología de sensores digitales, la radiación "de haz cónico" y algoritmos complejos realizados por computadora. ${ }^{2}$

La radiología es parte esencial en el proceso de diagnóstico del paciente odontológico. A pesar de que 
la combinación de proyecciones planas de transmisión de rayos-X y la radiografía panorámica puede ser adecuada en un gran número de situaciones clínicas, en algunos casos la evaluación radiográfica puede ser facilitada por imágenes multi-planos incluidas las tomografias computarizadas. ${ }^{1}$

El uso de técnicas de imagenología avanzada ha sido limitado debido a su alto costo, la disposición de infraestructura adecuada y la preocupación por las dosis de radiación; sin embargo, la introducción de tomografía computarizada de haz cónico para uso en la región maxilofacial provee al clínico la oportunidad de obtener imágenes multi-planos. ${ }^{2}$

El propósito de este artículo es revisar las ventajas que ofrecen los sistemas de tomografía computarizada de haz cónico en la región maxilofacial e ilustrar sobre las aplicaciones clínicas de estos sistemas en odontología.

\section{Historia}

Las bases teóricas de la reconstrucción tomográfica de imágenes fueron planteadas por Radon en 1917 cuando estableció que un objeto tridimensional puede ser reconstruido a partir de una serie infinita de proyecciones de dos dimensiones obtenidas en diferentes ángulos alrededor del objeto. ${ }^{1}$

El primer escáner de tomografía computarizada fue desarrollado por Sir Goldfrey Hounsfield. ${ }^{1,2}$ Desde entonces, la tecnología de tomografía computarizada atravesó cuatro generaciones de desarrollo bastante rápidas. La primera generación de escáner con un solo detector para capturar un haz de rayos$\mathrm{X}$, correspondía a la integral de los coeficientes de atenuación linear a lo largo de una línea única. Luego se trasladaba horizontalmente para adquirir la integral de la siguiente línea. Después de adquirir las integrales de todas las líneas para una posición dada del rayo $\mathrm{X}$, tanto el detector como la fuente rotaban un grado, un diseño conocido como escaneo de traslación-rotación. La unidad utilizada por Hounsfield perteneció a esta generación, así también como los primeros escáneres de tomografia computarizada introducidos al público y al comercio en 1972. Como dato interesante, estos primeros escáneres de tomografia computarizada fueron diseñados para escanear sólo la cabeza.

Los escáneres convencionales de tomografía computarizada son sistemas costosos y grandes diseñados para escaneo corporales totales a una gran velocidad para disminuir los artefactos producidos por el movimiento del corazón, los pulmones y los intestinos. Estos escáneres no son útiles para imágenes dentomaxilofaciales en donde el costo juega un factor muy importante, además de no disponerse de un espacio tan grande y que la zona estudiada está limitada a la cabeza. El advenimiento de la tomografia computarizada "de haz cónico" ha permitido el desarrollo de escáneres relativamente pequeños y menos costosos dedicados al uso en imagenología dentomaxilofacial. ${ }^{2}$

Datos estadísticos de la Comisión internacional de protección radiológica (ICRP) muestran que para1995 las tomografias computarizadas sólo en Estados Unidos se hacían a razón de 20 millones al año. Igualmente, se sabe que el incremento de este examen ha sido que en 1995 equivalía al $2 \%$ de todos los exámenes radiológicos y que para 2005 ya equivalía al $15 \%$ de todos los exámenes radiológicos. ${ }^{2}$

En odontología la tomografía computarizada de haz cónico fue introducida en Estados Unidos en el año 2000 y desde entonces las máquinas que se han instalado han ido en aumento, para 2005 había alrededor de $50 .^{2}$

\section{Principios de función}

Los escáneres de tomografía computarizada de haz cónico utilizan un detector bi-dimensional que con una sola rotación genera una imagen entera de una región de interés (Figura 1), mientras que los escáneres de tomografia computarizada convencional producen una imagen completa a partir de múltiples cortes que son superpuestos (Figura 2). Estos nuevos escáneres logran una alta eficiencia en el uso de rayos $\mathrm{X}$ y una rapidez inherente en la adquisición de datos volumétricos.

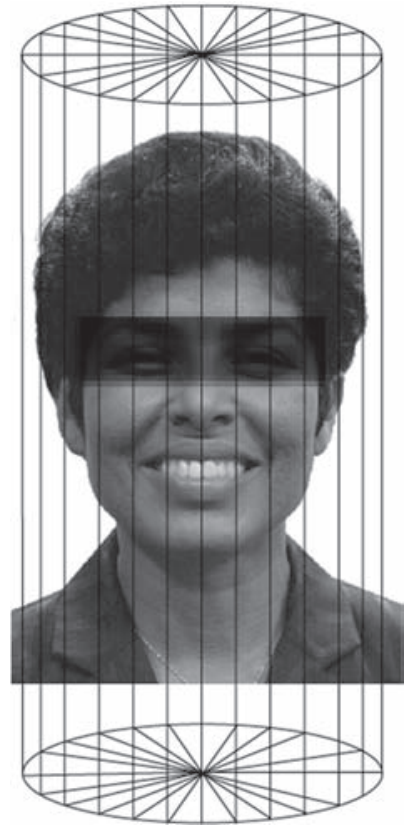

Figura 1. El haz cónico logra la imagen completa con una sola rotación del equipo. 


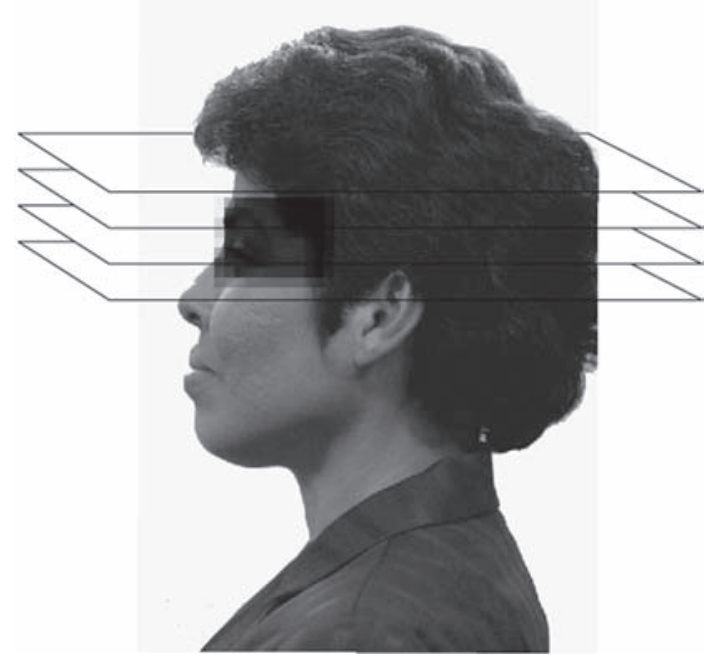

Figura 2. Los tomógrafos convencionales no requieren superponer los distintos cortes que realiza el equipo.

Los escaners convencionales de haz en abanico son obtenidos al iluminar un objeto con un haz de rayos $\mathrm{X}$ estrecho en forma de abanico. El haz de rayos $\mathrm{X}$ generado por el tubo es convertido en un haz de abanico al rechazar los fotones en la parte exterior del abanico, resultando en un uso altamente ineficaz de los fotones de rayos X. Además, el haz en abanico requiere reconstruir el objeto corte por corte y luego superponerlas para obtener una representación tridimensional del objeto. Cada corte individual requiere un escaneo separado y una reconstrucción bidimensional por separado. La técnica de haz cónico, por el contrario, requiere un solo escaneo para capturar un objeto entero con un cono de rayos $\mathrm{X}$ (Figura 3). Por tanto, el tiempo requerido para adquirir una proyección de haz cónico es igual que para una de haz en abanico, pero toma varios escaneos de haz en abanico para completar la imagen de un solo objeto por lo que el tiempo de adquisición de la imagen es mucho mayor en comparación con la técnica de haz cónico. A pesar de que es posible reducir el tiempo de adquisición con el método de haz en abanico al usar un tubo de rayos $\mathrm{X}$ de alto poder, esto aumenta el costo y el tamaño del escáner además de aumentar el consumo de electricidad, lo que hace este diseño poco útil. ${ }^{1}$

Lo escáneres de tomografía computarizada en haz cónico están basados en una tomografía volumétrica, con un detector de área con tecnología bidimensional digital extendida, $\mathrm{y}$ un haz de rayos $\mathrm{X}$ tridimensional. La técnica de haz cónico involucra un escaneo simple de 360 grados en donde la fuente de rayos $\mathrm{X}$ y un detector reciprocante de área se mueven alrededor de la cabeza del paciente, la cual es estabilizada por un cabezal (Figura 4). A ciertos intervalos de grados, se adquieren proyecciones de imágenes sencillas, conocidas como imágenes base las cuales son similares a imágenes radiográficas cefalométricas. ${ }^{3-5}$ Esta serie de proyecciones de imágenes base es llamada datos de proyección, a la cual se le aplican programas de computadora que utilizan algoritmos complejos para generar grupos de datos volumétricos tridimensionales. Estos datos volumétricos son utilizados para proveer la reconstrucción primaria de imágenes en tres planos ortogonales (axial, sagital, y coronal).

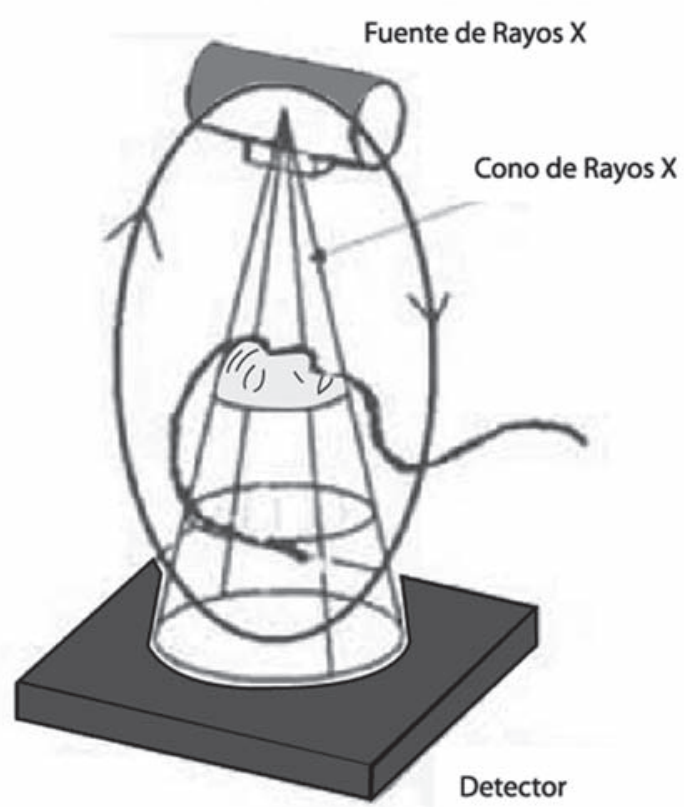

Figura 3. Los equipos de TCHC sólo requieren un escaneo del paciente.

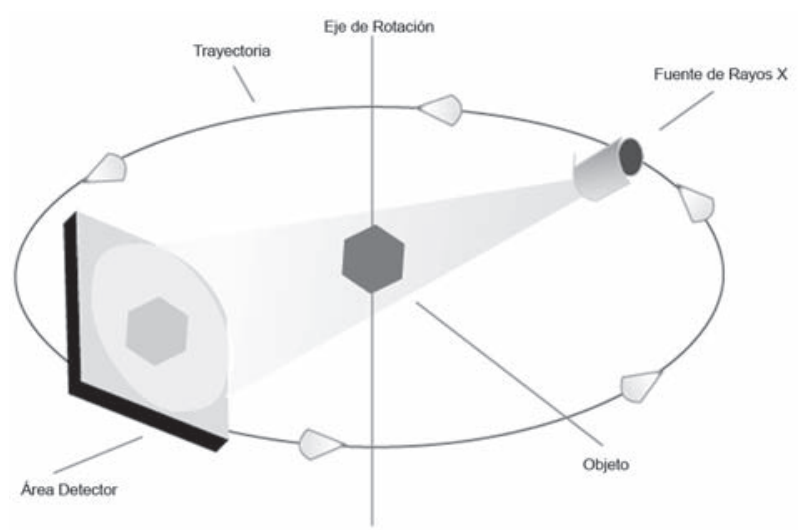

Figura 4. Dirección del eje del Rayo en un sistema TCHC.

A pesar de que la tomografía computarizada de haz cónico ha existido por dos décadas, su verdadero potencial está por verse. Recientemente ha sido posible desarrollar sistemas clínicos de tomografía computarizada de haz cónico que son menos 
costosos y de tamaño adecuado para ser usados en quirófanos, oficinas médicas, cuartos de urgencias, y salas de cuidados intensivos. ${ }^{6-8}$ Cuatro factores tecnológicos y específicos a su aplicación han coincidido para hacer esto posible. Primero, se ha desarrollado una variedad de detectores compactos planos de alta calidad. Segundo, las computadoras con especificaciones necesarias para la reconstrucción de imágenes por escaneo de haz cónico son ahora altamente disponibles y poco costosas. Tercero, los tubos de rayos $\mathrm{X}$ necesarios para el escaneo de haz cónico son considerablemente menos costosos que aquellos requeridos para la tomografía computarizada convencional. Cuarto, al centrarse en el escaneo de cabeza y cuello solamente, se logra eliminar la necesidad de velocidades de rotación por debajo de un segundo. Esto reduce considerablemente la complejidad y el costo de la tecnología.

Las imágenes con las que está familiarizado el clínico son los cortes axiales en "rebanadas" que se logran con la tomografia computarizada helicoide de haz en abanico. La tomografía computarizada de haz cónico permite la creación de imágenes en tiempo real no sólo en un plano axial sino también imágenes en dos dimensiones en los planos coronal, sagital, e inclusive hasta curvos u oblicuos: a este proceso se le denomina reconstrucción multiplanos o tridimensional.

\section{Diferencias entre la tomografía computariza- da de haz cónico y la tomografía axial tradi- cional}

- La tomografía computarizada de haz cónico utiliza menos radiación ya que se apoya en un intensificador de imagen.

- La tomografía computarizada de haz cónico obtiene una gran gama de imágenes con una sola escaneada. A diferencia de los equipos tradicionales que deben tomar sus imágenes de varias direcciones. ${ }^{9}$

- La tomografía computarizada de haz cónico proporciona excelente contraste entre los tejidos blandos, elimina todas esas imágenes borrosas y sobreimágenes de estructuras adyacentes. ${ }^{10}$

- La tomografía computarizada de haz cónico proporciona toma radiográfica de mayor ancho, lo que proporciona más información sobre estructuras como senos maxilares, la articulación temporomandibular y la anatomía de las vías aéreas. ${ }^{11-13}$

- En la tomografía computarizada de haz cónico se encontraron más hallazgos incidentales (son hallazgos que no están relacionados con la razón o causa de haber hecho la tomografía computarizada de haz cónica). ${ }^{14-18}$
- En la tomografía tradicional la fuente de los rayos $\mathrm{X}$ es un generador anodal rotatorio mientras que para la tomografía computarizada de haz cónico es un tubo anodal de baja energía similar al utilizado por los equipos panorámicos. ${ }^{19}$

- La tomografía tradicional utiliza un rayo en forma de abanico que viaja $360^{\circ}$ alrededor del paciente. La tecnología de la tomografía computarizada de haz cónico utiliza un rayo cónico con un intensificador especial de imágenes y un sensor de silicón especial. ${ }^{19}$

- La tomografía tradicional les toma las imágenes a los pacientes en una serie de planos axiales que son capturados ya sea como una pila de rebanadas o de un movimiento continuo en espiral sobre el plano axial. La tomografía computarizada de haz cónico utiliza un movimiento rotacional sobre el paciente, similar al de las radiografías panorámicas. Las imágenes pueden ser tomadas para una serie completa del sistema estomatognático o sólo para una porción del este sistema. ${ }^{19}$

\section{Exactitud de la tomografía computarizada de haz cónico}

Para comprender cómo funciona la tomografia computarizada de haz cónico primero se debe saber que los rayos $\mathrm{X}$ tradicionales siempre tienen cierto grado de error de proyección debido a que la región anatómica de interés está alejada de la película y esto se proyecta a la imagen. ${ }^{20}$ Las radiografias panorámicas tienen una proyección inusual ya que el camino del rayo $\mathrm{X}$ viene de una angulación ligeramente negativa. ${ }^{21}$ En la tomografía computarizada de haz cónico la proyección es ortogonal, lo que significa que los rayos $\mathrm{X}$ están paralelos los unos a los otros, además debido a que el objeto está muy cerca al sensor, hay poca proyección. ${ }^{22,23}$ Cualquier posible alteración, es manejada por el "software" o programa de la computadora. Todo esto hace que las imágenes que se obtienen tengan una relación de 1:1 con el objeto irradiado. Para disminuir al máximo cualquier posible error de calibración, estos equipos se autocalibran con un maniquí de agua.

Dykhouse y colaboradores encontraron que la tomografia computarizada de haz cónico era tan exacta a las radiografias periapicales para mostrar el tamaño y la presencia de cráteres óseos interproximales. $^{24}$ Sin embargo, por su capacidad de tridimensionalidad la tomografía computarizada de haz cónico fue superior a las radiografías periapicales a la hora de observar defectos óseos por vestibular o lingual. 


\section{Etapas en el proceso de la toma de la tomo- grafía computarizada de haz aónico}

1. El proceso de la toma de la tomografía computarizada de haz cónico se inicia con la remoción de cualquier metal (joyería, anteojos) que se encuentre en el área que se tomara la radiografia.

2. El escaneado de la máquina sólo toma alrededor de 10 a 70 segundos.

3. El técnico radiólogo podrá imprimir las imágenes tomadas o podrá quemar un disco compacto con todas las imágenes. Esta segunda opción tiene ventajas y desventajas. Abordemos primero las ventajas:

a. Usted tendrá a su disposición muchísima información sobre su paciente.

b. Es esta la información que llaman "hallazgos incidentales" y que puede encontrar otras anomalías que no se habían observado. Cha y colaboradores encontraron en promedio $24.6 \%$ de pacientes con hallazgos incidentales. La mayor área en donde encontraron hallazgos incidentales fue las vías aéreas superiores seguidas de la articulación temporomandibular y alteraciones endodónticas. ${ }^{14,25}$

Las desventajas son:

a. Usted tendrá que comprar el programa o "software" para manipular las imágenes en su consultorio. Se asume que usted no compró el equipo de tomografia, sino que un centro radiológico da el servicio.

b. Usted tendrá que entrenar a un personal de su consultorio para que realice todo este trabajo.

c. Al tener usted toda esta información sobre su paciente, existe el riesgo que por falta de conocimientos radiológicos, usted no observe alguna patología presente, lo cual puede traerle problemas legales.

\section{Usos de la tomografía computarizada de haz cónico}

La tomografía computarizada de haz cónico tiene muchas aplicaciones dentomaxilofaciales, entre las más útiles se encontró:

1. Estado de caninos impactados

2. Paredes de los senos nasales. ${ }^{26,27}$

3. Estructuras de las vías aéreas. ${ }^{28}$

4. Anatomía de la articulación temporomandibular. ${ }^{29}$

5. Predicción del crecimiento según la anatomía de las vértebras cervicales. ${ }^{30}$

6. Visualización del canal mandibular. ${ }^{31}$

7. Posición de los terceros molares.
8. Anatomía radicular de dientes y ápices.

En la figura 5, 6, 7 y 8 se observa un ejemplo de la calidad de las imágenes que produce una tomografía computarizada de haz cónico. Este es un paciente que mostró en la radiografía panorámica un problema con los caninos superiores permanentes. De la forma convencional hubiésemos tenido que tomarle una serie de radiografias para conocer más o menos su posición. Con la Tomografia Computarizada de Haz cónico se pueden obtener imágenes que permiten realizar un diagnóstico exacto de la patología.

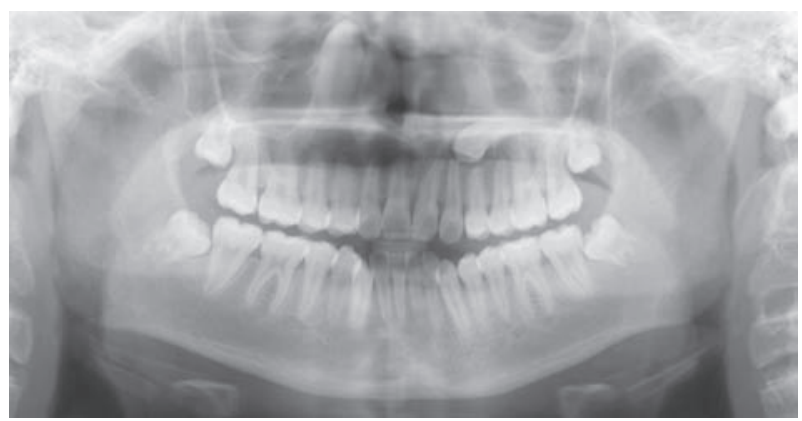

Figura 5. Caninos Superiores Incluidos. En una ortopantomografia no se puede determinar si está por vestibular o palatino. Cortesía Dr. Hugo Aguayo, Hanny González y Andrés Agurto (Perú).

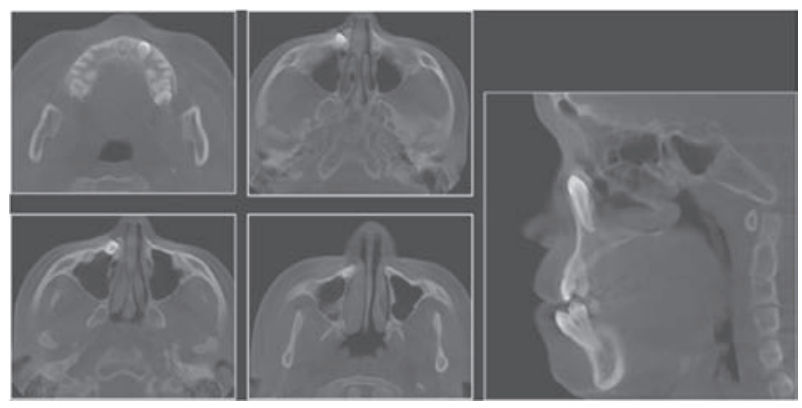

Figura 6. Diferentes vistas del TCHC que permiten localización exacta de caninos incluidos. Cortesía Dr. Hugo Aguayo, Hanny González y Andrés Agurto (Perú).

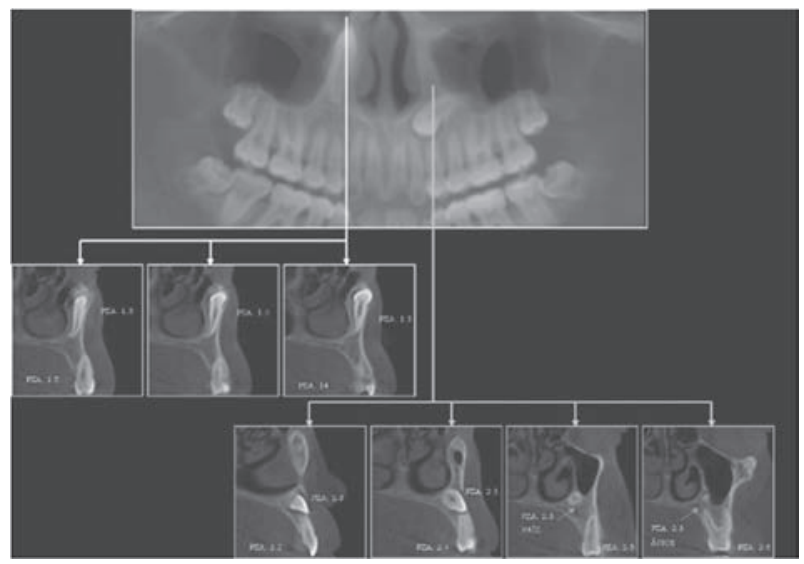

Figura 7. Corte Transversal a distintas distancias en el sistema TCHC. Las líneas amarillas y naranja establecen el lugar. Cortesía Dr. Hugo Aguayo, Hanny González y Andrés Agurto (Perú). 


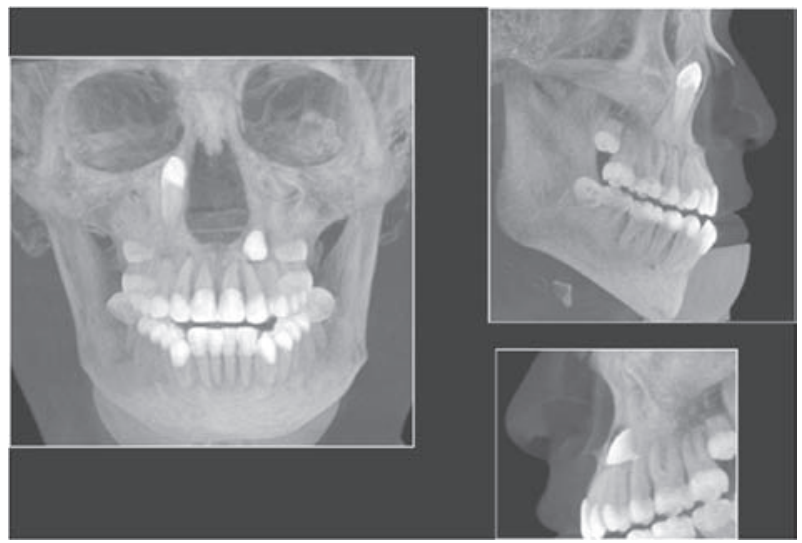

Figura 8. Imagen tridimensional realizada por el software a partir del escaneo del paciente. Cortesía Dr. Hugo Aguayo, Hanny González y Andrés Agurto (Perú).

\section{CONCLUSIONES}

1. La tomografía computarizada de haz cónico permite ver estructuras dentomaxilofaciales con un mejor contraste bidimensionalmente y también en los tres planos del espacio.

2. La mejor observación de todas las estructuras craneofaciales facilita y mejora el proceso diagnóstico.

3. Es una tecnología que debe ser más difundida y comercializada en el gremio odontológico, para que se comprenda mejor y sea más utilizada.

4. Por ser esta una tecnología que avanza de manera vertiginosa, el odontólogo debe buscar un especialista en radiológica para que realice el diagnóstico de este medio.

\section{Agradecimientos}

Al Dr. Alberto Barsallo (área de radiología. Facultad de Odontología, Universidad de Panamá). Al Dr. Hugo Aguayo, Hanny González y Andrés Agurto (Perú) por la cortesía de la tomografia computarizada de haz cónico y al Sr. Julio García por los diagramas.

\section{BIBLIOGRAFÍA}

1. Sukovic, P. Cone Beam Computed Tomography in Dentomaxillofacial Imaging”. AADMRT Newsletter. 2004.

2. Mah J, Hatcher D. Three-dimensional craniofacial imaging. Am J Orthod Dentofacial Orthop 2004; 126: 308 309.

3. Moshiri M, Scarfe W, Hilgers M, Scheetz J, Silveira A, Farman A. Accuracy of linear measurements from imaging plate and lateral cephalometric images derived from cone-beam computed tomography. Am J Orthod Dentofacial Orthop 2007; 132: 550 - 560 .

4. Kwong J, Palomo JM, Landers M, Figueroa A, Hans M. Image quality produced by different cone-beam computed tomography settings. Am J Orthod Dentofacial Orthop 2008; 133: 317 - 327.

5. Farman A, Scarfe W. Development of imaging selection criteria and procedures should precede cephalometric assessment with cone-beam computed tomography. Am J
Orthod Dentofacial Orthop 2006; 130: 257 - 265.

6. Silva MA, Wolf U, Heinicke F, Bumann A, Visser H, Hirsch E. Cone-beam computed tomography for routine orthodontic treatment planning: A radiation dose evaluation". Am J Orthod Dentofacial Orthop 2008; 133: 640.

7. Hilgers M, Scarfe W, Scheetz J, Farman A. Accuracy of linear temporomandibular joint measurements with cone beam computed tomography and digital cephalometric radiography. Am J Orthod Dentofacial Orthop 2005; 128: 803 - 811.

8. Cevidanes LH, Bailey LJ, Tucker SF, Styner MA, Mol A, Phillips CL, Proffit WR, Turvey T. Three-dimensional cone-beam computed tomography for assessment of mandibular changes after orthognathic surgery. Am J Orthod Dentofacial Orthop 2007; 131: 44 - 50.

9. Swennen G, Schutyser F. Three-dimensional cephalometry: Spiral multi-slice vs cone-beam computed tomography. Am J Orthod Dentofacial Orthop 2006; 130: 410 -416 .

10. Hujoel P, Hollender L, Bolen A, Young J, McGee M, Grosso A. Head-and-neck organ doses from an episode of orthodontic care. Am J Orthod Dentofacial Orthop 2008; 133: $210-217$.

11. Cevidanes LH, Styner MA, Proffit WR. Image analysis and superimposition of 3-dimensional cone-beam computed tomography models. Am J Orthod Dentofacial Orthop 2006; 129: 611 - 618.

12. Bida O, Scarfe W, Hilgers M, Kueber K, Silveira A, Haskell B, Farman A. Accuracy of cone-beam computed tomography imaging of the temporomandibular joint: Comparisons with panoramic radiology and linear tomography. Am J Orthod Dentofacial Orthop 2007; 132: 429 - 438.

13. Major MP, Flores-Mir C, Major P. Assessment of lateral cephalometric diagnosis of adenoid hypertrophy and posterior upper airway obstruction: A systematic review. Am J Orthod Dentofacial Orthop 2006; 130: 700 - 708.

14. Jung-Yui $C$, Mah J, Sinclair P. Incidental findings in the maxillofacial area with 3-dimensional cone-beam imaging. Am J Orthod Dentofacial Orthop 2007; 132: 7 - 14.

15. Turpin D. Befriend your oral and maxillofacial radiologist. Am J Orthod Dentofacial Orthop 2007; 131: 697.

16. Geist J. Oral and maxillofacial radiologists ready to help. Am J Orthod Dentofacial Orthop 2007; 132: 569 - 570.

17. Chen C, Decker J. Letter to the editor. Am J Orthod Dentofacial Orthop 2007; 132: 277.

18. Henry K. "10 tips from a trial lawyer". Dental Economics [en línea] 2008. URL disponible en: http://www.dentaleconomics.com/articles/article_display.html?id =332788

19. Pompa Sarah. Reading 3D Data. Orthodontic Products. Nov. 2007. pag. 16-23.

20. Erickson MJ. Cone beam computerized tomography and digital radiography. A comparative study of posteroanterior cephalometrics. Am J Orthod Dentofacial Orthop 2005; 128: 549 - 564.

21. Hutchinson SY. Cone beam computed tomography panoramic images vs. traditional panoramic radiographs. Am J Orthod Dentofacial Orthop 2005; 128: 550 - 555.

22. King K. Paramedian palate morphology in the adolescent: a cone beam computed tomography study. Am J Orthod Dentofacial Orthop 2005; 128: 262 - 266.

23. Lane C, Harrell W. Completing the 3-dimensional picture. Am J Orthod Dentofacial Orthop 2008; 133: 612 - 620. 
24. Dykhouse V, Moffit A, Grubb J, Greco P, English J, Briss B, Jamieson S, Kastrop M, Owens E. A revision of the adult intraoral radiograph protocol for $\mathrm{ABO}$ clinical examinations". Am J Orthod Dentofacial Orthop 2007; 131: 303 $-304$.

25. Kuftinec M. Liability regarding computerized axial tomography scans. Am J Orthod Dentofacial Orthop 2007; 132: 569.

26. King K, Lam E, Faulker M, Heo G, Major P. Vertical bone volume in the paramedian palate of adolescents: A computed tomography study. Am J Orthod Dentofacial Orthop 2007; 132: 783 - 788.

27. Rungcharassaeng K, Caruso J, Kan J, Kim J, Taylor G. Factors affecting buccal bone changes of maxillary posterior teeth after rapid maxillary expansion. Am J Orthod Dentofacial Orthop 2007; 132: 428.

28. Lagravere M, Major P. Proposed reference point for 3-dimensional cephalometric analysis with cone-beam computerized tomography. Am J Orthod Dentofacial Orthop 2005; 128: 657 - 660.

29. Hilgers M, William C, Scheetz J, Farman A. Accuracy of linear Temporomandibular joint measurements with cone beam computed tomography and digital cephalometric radiography. Am J Orthod Dentofacial Orthop 2007; 128; 803 - 811.

30. Shi H, Scarfe W, Farman A. Three-dimensional reconstruction of individual cervical vertebrae from cone-beam computed-tomography images". Am J Orthod Dentofacial Orthop 2007; 13: 426 -432.

31. Seong-Hun K, Yong-Suk C, Eui-Hwan H, Kyu-Rhim C, Yoon-Ah K, Gerald N. Surgical positioning of orthodontic mini-implants with guides fabricated on models replicated with cone-beam computed tomography.. Am J Orthod Dentofacial Orthop 2007; 131: S82 - S89.

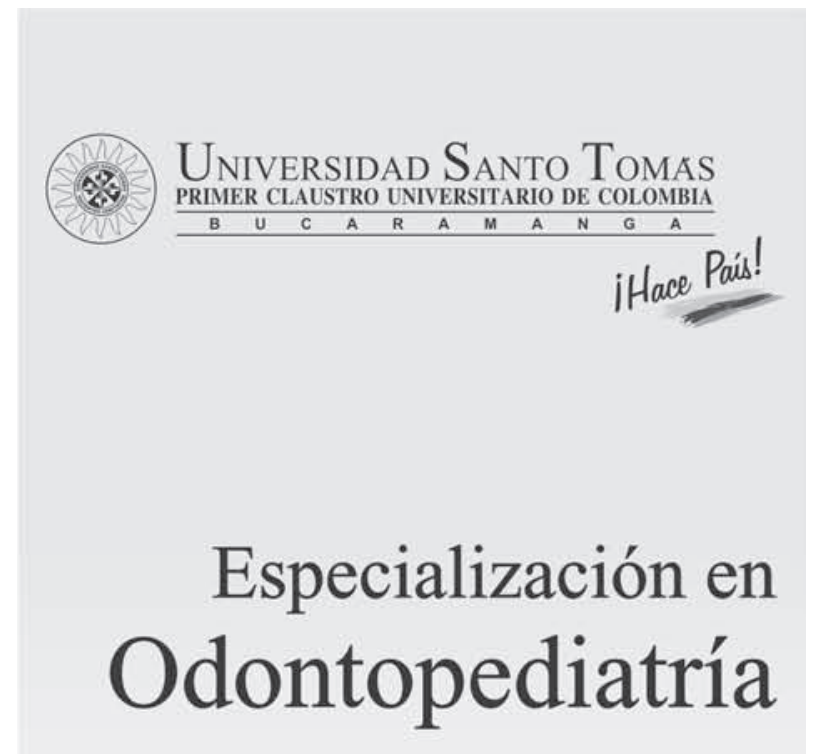

\section{ODONTOLOGÍA INFANTIL}

\section{Servicios de Odontopediatría y Ortodoncia Preventiva}

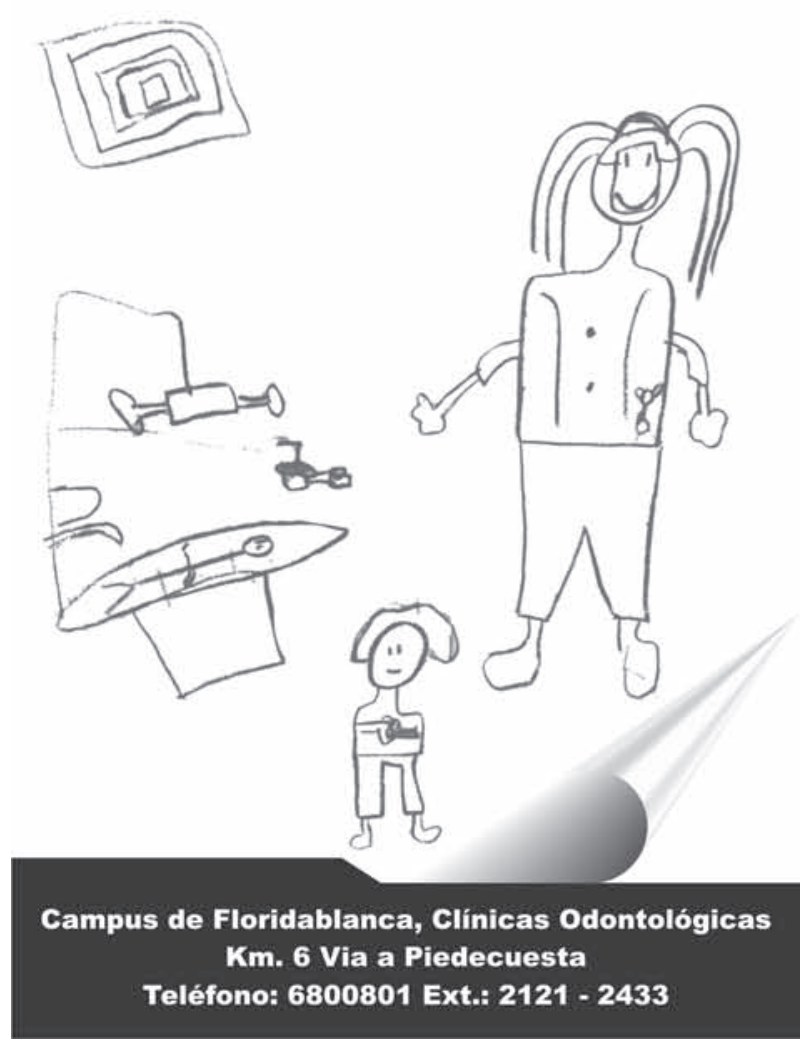

